\title{
Gaps-in-Noise Measurement of the Elderly as a Function of Stimulus Level
}

\author{
Kyoung Min Park',2, Jae Hee Lee ${ }^{2}$ \\ ${ }^{1}$ Soree Ear Clinic, Seoul, Korea \\ ${ }^{2}$ Department of Audiology, Hallym University of Graduate Studies, Seoul, Korea
}

\author{
자극제시레벨에 따른 노인의 Gaps-in-Noise 측정에 관한 연구 \\ 박 경 민 ${ }^{1,2} \cdot$ 이 재 희 ${ }^{2}$ \\ 소리이비인후과 ${ }^{1}$, 한림국제대학원대학교 청각학과 ${ }^{2}$
}

\begin{abstract}
Purpose: The gaps-in-noise (GIN) test was developed as a clinical evaluation of temporal resolution. In the GIN test, a sensation level of $50 \mathrm{~dB} S \mathrm{SL}$ was recommended as a standard clinical presentation level to ensure stimulus audibility. It has been reported that the stimulus level less than $30 \mathrm{~dB}$ SL should not be used as presentation level to verify a proper level for administration of GIN test. Given that the previous finding was based on the data of young normal-hearing adults, the present study aimed to compare the GIN results as a function of stimulus level in listener groups differing in age and hearing sensitivity. Methods: Participants were 10 young normal-hearing (YNH), 12 elderly normal-hearing, and 12 elderly hearing-impaired (EHI) listeners. GIN was administered at 20, 30, 40, and $50 \mathrm{~dB}$ SL. The performance was determined from both the approximate threshold and the percentage of correct gap. Results: As results, both approximate threshold and percent correct in GIN results were measured. Results showed that, overall, both the threshold as well as the percent correct in GIN improved with increasing stimulus level. Across groups, EHI showed the poorest results from GIN test, with the best performance in $\mathrm{YNH}$. EHI listeners with greater hearing loss at higher frequencies $(2-8 \mathrm{kHz})$ were poorer at detecting gaps in noise. Across a range of stimulus level (20-50 dB SL), the GIN performance between 40 and $50 \mathrm{~dB} S \mathrm{SL}$ did not differ in all listener groups. Conclusion: A sensation level of 35-50 dB may be applicable to the elderly with normal hearing or slight-to-mild degree of hearing loss, without significant change in GIN performance.
\end{abstract}

Key Words: Stimulus level, Auditory temporal processing, Temporal resolution, The elderly.

Received: October 22, 2015 / Revised: November 17, 2015 / Accepted: December 21, 2015

Correspondence: Jae Hee Lee, Department of Audiology, Hallym University of Graduate Studies, 405 Yeoksam-ro, Gangnam-gu, Seoul 06198, Korea Tel: +82-2-2051-4952 / Fax: +82-2-3451-6618 / E-mail: leejaehee@hallym.ac.kr

\section{INTRODUCTION}

시간정보처리(temporal processing)능력이란 소리의 시간적 구조 및 정보를 정확하고 신속하게 처리하는 것으로 이는 실시 간으로 빠르게 변화하는 언어적, 비언어적 음향신호의 탐지 및 처리능력과 관련된다(Snell \& Frisina, 2000; Choi et al., 2013). Gap 탐지역치(gap detection threshold, GDT)는 시간적 분석 능력을 측정하는 대표적인 방법 중 하나로 두 개의 연속된 자 극음 중간에 위치한 휴지기간(silence), 즉 gap을 제시한 후 청 자가 얼마나 짧은 gap까지 탐지할 수 있는지를 역치로 측정하 는 것이다. 다양한 청각 및 심리음향 연구에서 순음, 협대역 및 광대역 잡음 등의 자극음을 사용하여 gap의 위치, 길이, 주파
수, 강도, 전체 자극음 제시시간 등을 변화하여 GDT를 측정하 였다(Schneider \& Hamstra, 1999; Bertoli et al., 2005; Harris et al., 2010). 또한 건청성인보다 건청노인군의 GDT가 유의하게 크고(Schneider et al., 1994; Snell \& Frisina, 2000; Heinrich \& Schneider, 2006; Harris et al., 2010), 건청인에 비해 난청인 의 GDT가 유의하게 커(Moore et al., 1989; Grose \& Hall, 1996; Hall et al., 1998; Ok \& Lim, 2007) 노화와 난청 모두 GDT에 부정적인 영향을 미칠 수 있다는 연구결과가 보고된 바 있다.

2005년 Musiek et al.은 연구분야뿐 아니라 임상에서도 gap 탐지능력을 쉽고 빠르게 중추청각처리장애 선별이 가능한 gaps-in-noise(GIN) 평가를 개발하였다. GIN 검사 시 충분히 
들을 수 있는 레벨에서 자극음을 들려주어야 가청(audibility) 정도가 GIN 결과에 영향을 주지 않으므로 청자 개개인의 평균 순음역치(pure tone average, PTA) 혹은 어음인지역치(speech recognition threshold, SRT)보다 $50 \mathrm{~dB}$ hearing level(HL) 큰 강도, 즉 $50 \mathrm{~dB}$ sensation level(SL)에서 자극음을 제시할 것을 권고하였다. GIN 개발 후 그 후속 연구로 Weihing et al.(2007) 은 자극음의 제시레벨을 변화하여 $(5 \sim 50 \mathrm{~dB} \mathrm{SL})$ 자극제시레벨 이 건청성인 $(\mathrm{n}=10)$ 의 GIN 결과에 영향을 미치는지 확인하고 자 하였다. 분석 결과 $35 \mathrm{~dB}$ SL과 $50 \mathrm{~dB}$ SL 간 $\mathrm{GIN}$ 결과는 유 의하게 다르지 않았으나, $35 \mathrm{~dB}$ SL에서 $5 \mathrm{~dB}$ SL로 자극제시레 벨이 점차 감소할수록 $\mathrm{GIN}$ 수행력이 유의하게 저하되었다. 따 라서 $30 \mathrm{~dB} \mathrm{SL}$ 이하의 자극제시레벨에서 자극음을 제시하지 않아야 함을 확인하였다. 그러나 이는 건청성인 10 명의 자료에 기준한 것이므로 더 다양한 청자군을 대상으로 한 연구가 지 속되어야 함을 밝혔다.

건청청년의 결과를 기준으로 한 최소 $35 \mathrm{~dB} \mathrm{SL} \mathrm{최대} 50 \mathrm{~dB}$ $\mathrm{SL}$ 의 제시레벨 권고사항이 건청 혹은 난청노인군을 대상으로 도 적용이 가능한지 알아보기 위해 $20,30,40,50 \mathrm{~dB} \mathrm{SL}$ 의 다 양한 자극제시레벨에서 GIN 검사를 시행하여 자극음 제시레 벨에 따른 GIN 백분율(percent correct score) 및 추정역치(approximated gap detection threshold, A. th.)를 비교하고자 하 였다. 선행연구(Musiek et al., 2005)에서 권고된 GIN 평가절차 에 따라 $50 \mathrm{~dB}$ SL에서 $\mathrm{GIN}$ 평가를 시행하였음에도, 즉 역치 를 기준으로 충분히 들을 수 있는 조건에서도 노인 청자의 주 파수별 역치가 GIN 결과와 연관성을 가지는지 상관분석을 추 가로 시행하였다.

\section{MATERIALS AND METHODS}

\section{연구대상}

본 연구의 대상자는 총 34명으로 건청성인(young normalhearing, YNH) 10명(평균 연령 25세, 연령 범위 23 28세, 남 3, 여 7), 건청노인(elderly normal-hearing, ENH) 12 명(평균 연령 63세, 연령 범위 60 65세, 남 1, 여 11), 난청노인(elderly hearing-impaired, EHI) 12명(평균 연령 66세, 연령 범위 60 73세, 남 3, 여 9)이었다. 실험 전 각 대상자의 $250 \mathrm{~Hz} 8,000 \mathrm{~Hz}$ 이내 옥타브 단위의 주파수별 순음청력역치와 SRT를 측정하였다 (GSI 61; Grason-Stadler, Madison, IL, USA). 본 연구에 참여 한 대상자 모두 양측 귀의 중이검사 결과(GSI TympStar; Grason-Stadler) A형의 고막운동도를 보였고, 어지러움, 이명, 신경 학적 병력을 가지지 않은 오른손잡이 대상자였다. 대상자 모두 연구참여 전 연구의 목적 및 절차에 대한 설명을 듣고 연구참 여 동의서에 서명을 하였다.
$\mathrm{YNH}, \mathrm{ENH}, \mathrm{EHI}$ 군의 검사 귀의 주파수별 청력역치를 Figure 1 에 제시하였다. 먼저, YNH 대상자는 10 명 모두 전 주파수에 서 양이 $20 \mathrm{~dB} \mathrm{HL}$ 이하의 청력을 보였고, 10 명 중 무작위로 선 택한 5명은 오른쪽 귀를, 나머지 5명은 왼쪽 귀를 검사 귀로 하 였다. 12명의 ENH 대상자의 경우 Bahng \& Lee (2015)가 제시 한 남녀 노인의 연령별 청력역치 분포 자료를 기준하여 0.25 8 $\mathrm{kHz}$ 이내 청력역치가 제 1 사분위수 중위수에 포함되는 귀를 검사 귀로 하였다. 이 기준으로 12 명의 $\mathrm{ENH}$ 중 6 명은 오른쪽 귀, 나머지 6 명은 왼쪽 귀를 검사 귀로 하였다. $0.25,0.5,1,2$, $4,8 \mathrm{kH}$ 의 주파수에서 측정한 $\mathrm{ENH}$ 군의 검사 귀 순음청력역치 는 $15,13,14,11,16,27 \mathrm{~dB}$ HL이었다(검사 귀의 $0.5,1,2 \mathrm{kHz}$ PTA: 13 dB HL; 1, 2, 4 kHz PTA: 14 dB HL; SRT: $10 \mathrm{~dB}$ $\mathrm{HL}$. 마지막으로, 12 명의 EHI 대상자는 양이 모두 저주파수에 서 고주파수로 갈수록 청력이 떨어지는 경사형 감각신경성 난 청을 가지고 있었다. 양이의 청력 정도와 유형을 고려하여 경사 형 경중도 감각신경성 난청을 보이는 귀를 검사 귀로 하였고, 12 명 중 6 명의 검사 귀는 오른쪽 귀, 나머지 6 명의 검사 귀는 왼쪽 귀였다. Figure 1에서 제시했듯이 $0.25,0.5,1,2,4,8 \mathrm{kH}$ 의 주파수에서 측정한 $\mathrm{EHI}$ 군의 검사 귀 순음청력역치는 20,21 , $30,36,48,51 \mathrm{~dB}$ HL이었다(검사 귀의 $0.5,1,2 \mathrm{kHz}$ PTA: 29 $\mathrm{dB}$ HL; 1, 2, 4 kHz PTA: $38 \mathrm{~dB}$ HL; SRT: $21 \mathrm{~dB}$ HL). 두 노 인군(ENH, EHI)의 주파수별 청력역치를 종속변수로 독립표 본 $t$ 검정을 실시한 결과 $0.25 \mathrm{kHz}$ 를 제외한 모든 주파수에서 $\mathrm{ENH}$ 군보다 $\mathrm{EHI}$ 군의 청력이 유의하게 더 나빴다 $(p<0.05)$.

추가적으로 $\mathrm{ENH}$ 와 $\mathrm{EHI}$ 대상자에게 Mini-Mental State Examination Korean version(MMSE-K)(Kwon \& Park, 1989)과 순방향, 역방향 숫자기억능력검사를 시행하였다. MMSE-K 측 정 결과 노년 대상자 모두 치매진단 절단점인 24점 이상의 점수 (24 z: no cognitive impairment)(Folstein et al., 1975)를 보

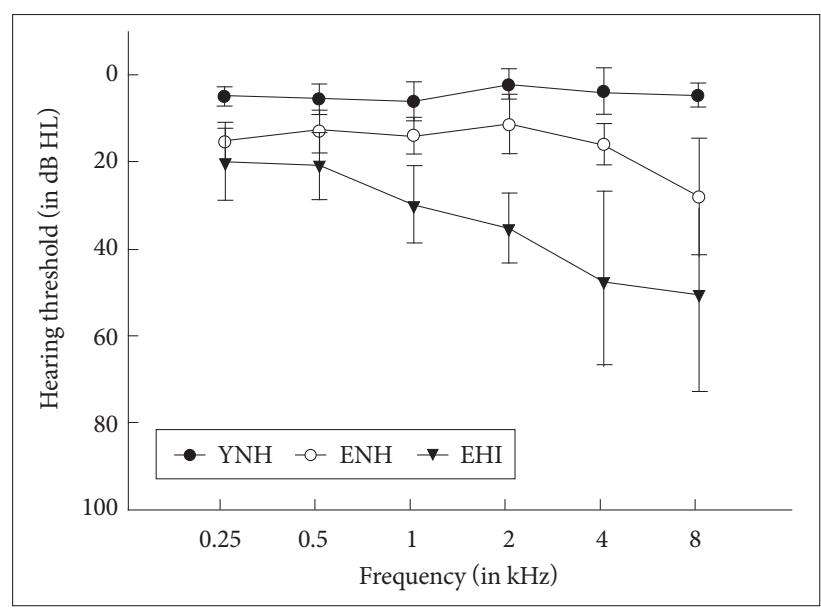

Figure 1. Mean audiometric thresholds of test ear for young normal-hearing $(\mathrm{YNH})$, elderly normal-hearing $(\mathrm{ENH})$, elderly hearing-impaired (EHI) groups. 
여 정상 인지기능을 가졌음을 확인하였다. $\mathrm{ENH}$ 군과 $\mathrm{EHI}$ 군이 순방향으로 옳게 기억할 수 있는 숫자는 평균 6개, 역방향의 경 우 평균 3 개로 두 그룹 간 결과가 같았다.

\section{연구절차}

본 연구에서는 상용화된 GIN 검사도구(Auditec Inc., St. Louis, MO, USA)와 노트북(SENS P55, Samsung, Electronics Co., Suwon, Korea), 청력검사기(GSI 61, Grason-Stadler), 헤 드폰(TDH-39, Telephonics Corporation, Farmingdale, NY, USA)을 통해 GIN 평가를 시행하였다. GIN은 총 4개의 검사 목록과 1개의 연습용 목록으로 구성되어 있다. 자극음으로 6 초의 백색잡음(white noise) 내에 0 3개의 gap이 제시되며, 검 사목록당 총 10 개의 다양한 지속시간 $(2,3,4,5,6,8,10,12$, $15,20 \mathrm{msec}$ )의 gap이 무작위 순서로 각각 6 회 제시된다(목록 당 총 60개의 gap). 대상자는 제시된 자극음을 듣고 gap을 탐 지하자마자 버튼을 눌러 반응하도록 하였다. gap 제시 후 1 초 이내에 반응하지 않으면 gap을 탐지하지 못한 것으로 간주하 므로 피검자가 올바르게 탐지 유무를 반응할 수 있도록 연습 (practice)용 GIN 음원을 통한 사전연습을 시행하였다.

본 연구에서는 GIN 개발 연구자들(Musiek, 2005; Weihing et al., 2007)이 권고한 $50 \mathrm{~dB}$ SL뿐아니라 20, 30, $40 \mathrm{~dB}$ SL을 포함하여 총 4가지 제시레벨에서 무작위 순서로 자극음을 제 시하여 GIN 검사를 시행하였다. GIN 평가절차에 따라 GIN 백분율(percent correct)과 GIN 추정역치(A. th.), 두 가지 방법 으로 청자의 gap 탐지능력을 평가하였다. 2 20 msec의 다양한 길이의 gap이 6회 제시되었으므로 총 제시된 gap 개수 중 옳게 탐지한 gap의 수를 계산하여 GIN 백분율(percent correct)을 계산하였고 6회 제시된 gap 중 최소 4회 옳게 탐지할 수 있는 가장 짧은 gap의 길이를 GIN 추정역치(msec)로 평가하였다.

\section{통계분석}

수집된 결과는 SPSS version 20.0(IBM Corp., Armonk, NY, USA) 소프트웨어를 이용하여 분석하였다. 본 연구에서는 그룹 내 독립변수인 자극음 제시레벨 $(20,30,40,50 \mathrm{~dB} \mathrm{SL})$ 과 그룹 간 독립변수인 그룹(건청청년, 건청노인, 난청노인)이 GIN 백분 율(\%)과 GIN 추정역치(msec)의 종속변수에 미치는 영향을 확 인하기 위해 반복측정된 이원배치 분산분석(two-way analysis of variance with repeated measures)을 실시하였다. 자극제 시레벨이 각 세 그룹의 결과에 미치는 영향을 추가로 사후분석 할 필요가 있을 경우 반복측정된 일원배치 분산분석(one-way analysis of variance with repeated measures)을 시행하였다. 노 인대상군의 경우 추가로 Pearson 상관분석을 실시하여 각 제 시레벨에서 측정한 GIN 결과와 주파수별 순음청력역치 혹은
$\mathrm{PTA}$ 와의 상관성을 확인하였다. 모든 통계분석은 유의수준 0.05 를 기준으로 하였고, 반복측정된 이원분산분석 시 Mauchly 구형성 가정에 위배될 경우 Greenhouse-Geisser 수 정된 자유도와 $\mathrm{F}$ 값을 보고하였다.

\section{RESULTS}

\section{평균 GIN 백분율(percent correct)과 추정역치(A. th.) 비교}

세 그룹(YNH, ENH, EHI)의 평균 GIN 백분율(percent correct)은 Figure 2에, 평균 GIN 추정역치는 Figure 3에 나타 냈다. Figure 2에 제시한 바와 같이 20, 30, 40, $50 \mathrm{~dB}$ SL에서 측정한 $\mathrm{YNH}$ 군의 평균 $\mathrm{GIN}$ 백분율은 $56,65,72,76 \%$ (표준 편 차: 7.7, 7.2, 6.2, 3.5)였다. 동일 레벨에서 측정한 $\mathrm{ENH}$ 군의 평균 $\mathrm{GIN}$ 백분율은 $44,52,56,58 \%$ (표준 편차: $14.5,14,12.6,10.4$ ), $\mathrm{EHI}$ 군의 경우 평균 $31,39,42,44 \%$ (표준 편차: $11.2,13,11.6$, 9.7)의 결과를 보였다. 분석 결과 그룹 간 백분율이 유의하게 달 랐으며 $[\mathrm{F}(2,31)=21]$, Bonferroni 사후분석 결과 $\mathrm{EHI}$ 군보다 $\mathrm{ENH}$ 군의 수행능력이 유의하게 좋았고 $\mathrm{ENH}$ 군보다 $\mathrm{YNH}$ 군의 결과가 유의하게 좋았다. 자극음 제시레벨이 GIN 백분율에 미

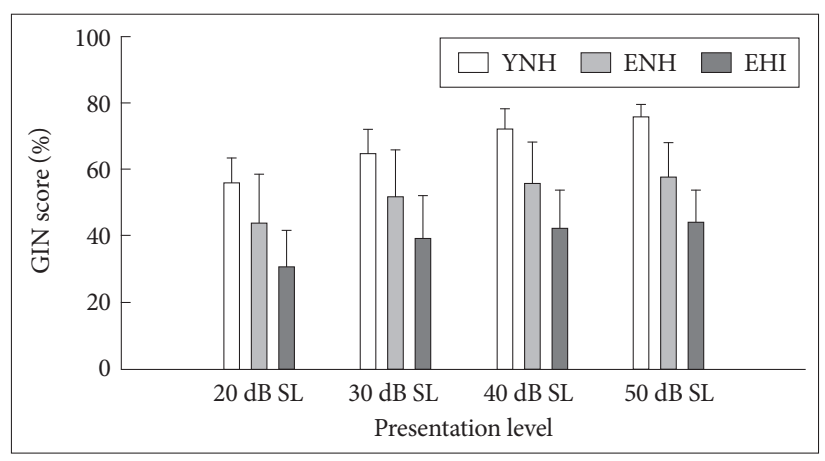

Figure 2. Mean values of GIN (gaps-in-noise) scores measured at 20,30, 40, and $50 \mathrm{~dB}$ SL for young normal-hearing (YNH), elderly normal-hearing $(\mathrm{ENH})$, elderly hearing-impaired (EHI) groups (error bar: standard deviation).

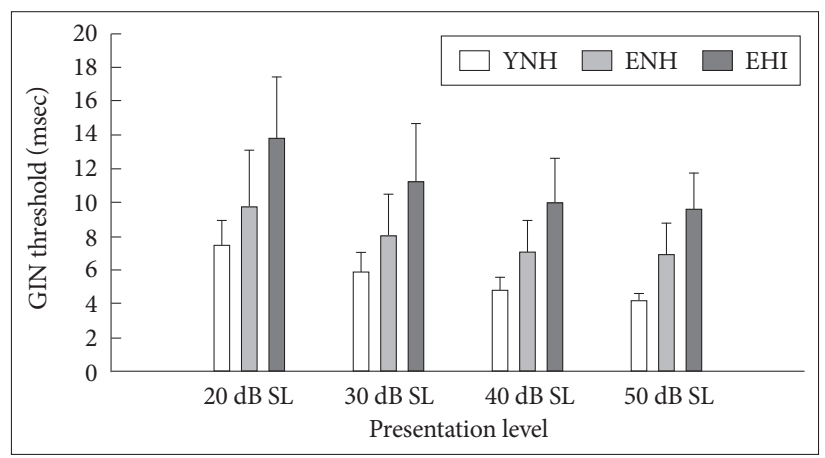

Figure 3. Mean values of GIN (gaps-in-noise) threshold measured at 20,30,40, and $50 \mathrm{~dB}$ SL for young normal-hearing $(\mathrm{YNH})$, elderly normal-hearing $(\mathrm{ENH})$, elderly hearing-impaired (EHI) groups (error bar: standard deviation). 
치는 주효과 또한 유의하였고 $[\mathrm{F}(2,61.6)=85.1]$, Bonferroni 대 응비교 분석 결과 네 가지 자극제시레벨의 모든 결과가 서로 유 의하게 달랐음을 확인하였다. 전체적으로 자극음 제시레벨이 $20,30,40,50 \mathrm{~dB}$ SL로 증가할수록 세 그룹의 GIN 백분율이 모두 증가하는 유사한 패턴을 보여 그룹과 자극제시레벨 간 이 원상호작용은 유의하지 않았다 $[\mathrm{F}(4,61.6)=1.8]$.

Figure 3에 제시하였듯이, 20, 30, 40, 50 dB SL에서의 YNH 군 평균 $\mathrm{GIN}$ 추정역치는 7.5, 5.9, 4.8, $4.2 \mathrm{msec}$ (표준 편차: 1.4 , $1.2,0.8,0.4)$ 이었고, $\mathrm{ENH}$ 군의 추정역치는 평균 9.8, 8.1, 7.1, $6.9 \mathrm{msec}($ 표준 편차: $3.4,2.4,1.9,1.9)$, $\mathrm{EHI}$ 군의 평균 $\mathrm{GIN}$ 추정 역치는 13.8, 11.3, 10, $9.6 \mathrm{msec}$ (표준 편차: 3.6, 3.4, 2.7, 2.2)이 었다. GIN 추정역치를 종속변수로 한 분석 결과 그룹 $[\mathrm{F}(2,31)$ $=19.1]$ 과 제시레벨 $[\mathrm{F}(2.1,66.3)=50.3]$ 에 따라 GIN 추정역치 는 유의하게 달랐다. GIN 백분율 결과와 마찬가지로 $\mathrm{EHI}$ 군보 다 $\mathrm{ENH}$ 군의 GIN 추정역치가 더 짧았고(좋았고), $\mathrm{ENH}$ 군보다 $\mathrm{YNH}$ 군의 GIN 추정역치가 유의하게 더 짧았다. 4 가지 자극제 시레벨 간에는 $40,50 \mathrm{~dB} \mathrm{SL}$ 간 결과는 유의하게 다르지 않았 고 나머지 레벨 간 결과는 서로 유의하게 달랐다. 전체적으로 자극음 제시레벨이 $20,30,40,50 \mathrm{~dB}$ SL으로 증가할수록 세 그룹의 GIN 추정역치가 점차 감소하는 유사한 패턴을 보여 그 룹과 자극제시레벨 간 이원상호작용은 유의하지 않았다 $[\mathrm{F}(4.3$, 66.3) $=0.9]$.

본 연구에서 중점을 둔 것이 선행연구에서 건청청년의 결과 를 기준으로 한 최소 $35 \mathrm{~dB} \mathrm{SL}$ 최대 $50 \mathrm{~dB} \mathrm{SL}$ 의 제시레벨 권 고사항이 건청노인 혹은 난청노인에게도 동일하게 적용 가능한 지를 알아보는 것이었다. 따라서 자극제시레벨이 각 세 그룹의 결과에 미치는 영향을 추가 분석할 필요가 있었다. 이를 위해 각 그룹의 GIN 백분율을 종속변수로 자극음 제시레벨을 독립 변수로 하여 반복측정된 일원배치 분산분석을 시행하였다. 먼 저 $\mathrm{YNH}, \mathrm{ENG}$ 군 모두 $20 \mathrm{~dB} \mathrm{SL} \rightarrow 30 \mathrm{~dB} \mathrm{SL}, 30 \mathrm{~dB} \mathrm{SL} \rightarrow 40$ $\mathrm{dB}$ 로 강도가 증가할수록 $\mathrm{GIN}$ 정반응률이 유의하게 향상하였 으나, $40 \mathrm{~dB}$ SL과 $50 \mathrm{~dB}$ SL에서 측정된 $\mathrm{GIN}$ 백분율 결과는 유의하게 다르지 않았다. $\mathrm{EHI}$ 군의 경우 $20 \mathrm{~dB} \mathrm{SL} \rightarrow 30 \mathrm{~dB} \mathrm{SL}$ 로 증가할수록 $\mathrm{GIN}$ 결과가 유의하게 향상하였으나, 30 50 dB SL에서 측정된 GIN 정반응률은 유의하게 다르지 않았다. 선 행연구에서 발표한 최소 $35 \mathrm{~dB} \mathrm{SL}$ 이상의 레벨에서 자극음을 제시하여야 한다는 권고사항이 본 연구에 참여한 건청노인, 경 중도 난청노인 대상자의 결과에서도 유사하였음을 확인할 수 있었다.

\section{노인군의 순음청력역치와 GIN 결과 간 상관관계}

본 연구에는 건청노인, 난청노인 대상자가 모두 참여하였으 므로 그룹 간 뿐만 아니라 그룹 내 개개인의 주파수별 순음청
Table 1. Pearson correlation coefficients between GIN scores (\%) measured at 20, 30, 40, and $50 \mathrm{~dB}$ SL and PTA

\begin{tabular}{ccc}
\hline & $0.5,1,2 \mathrm{kHz}$ PTA & $1,2,4 \mathrm{kHz}$ PTA \\
\hline GIN score & & \\
at $20 \mathrm{~dB} \mathrm{SL}$ & $-0.41^{*}$ & $-0.56^{\dagger}$ \\
at $30 \mathrm{~dB} \mathrm{SL}$ & $-0.41^{*}$ & $-0.55^{\dagger}$ \\
at $40 \mathrm{~dB} \mathrm{SL}$ & $-0.52^{\dagger}$ & $-0.61^{\dagger}$ \\
at $50 \mathrm{~dB} \mathrm{SL}$ & $-0.62^{\dagger}$ & $-0.68^{\dagger}$ \\
\hline
\end{tabular}

${ }^{*} p<0.05,{ }^{\dagger} p<0.01$. GIN: gaps-in-noise, PTA: puretone threshold average

력역치에 차이가 있었다. 여러 주파수의 순음청력역치 중 특정 주파수의 순음역치가 GIN 결과를 더 잘 예측할 수 있는지, 혹 은 청력과 GIN 결과는 상관성을 가지지 않는지를 확인하고자 하였다. $0.25 \sim 8 \mathrm{kHz}$ 이내 옥타브 단위 주파수 중 $20,30,40$, $50 \mathrm{~dB}$ SL에서 측정된 GIN 정반응률과 모두 유의한 상관성을 보인 주파수는 $2 \mathrm{kHz}(-0.65<\mathrm{r}<-0.46), 4 \mathrm{kHz}(-0.65<\mathrm{r}$ $<-0.60), 8 \mathrm{kHz}(-0.56<\mathrm{r}<-0.42)$ 였다. 다시 말해, $2 \mathrm{kHz}$ 이상의 주파수에서 청력이 좋은 노인 대상자일수록 자극제시레 벨에 상관없이 GIN 수행력이 더 좋았음을 의미한다. Table 1은 노인대상군(ENH, $\mathrm{EHI})$ 의 $20,30,40,50 \mathrm{~dB}$ SL에서 측정된 GIN 정반응률과 $0.5,1,2 \mathrm{kHz}$ 의 평균순음역치 혹은 $1,2,4 \mathrm{kHz}$ 의 고주파수 평균순음역치 간 Pearson 상관계수를 보여준다.

\section{DISCUSSIONS}

GIN은 청자가 얼마나 짧은 gap을 탐지할 수 있는지를 역치 (msec)로 측정하여 약 17분 안에 신뢰도 있게(67\% 민감도, 94\%의 특이도) 중추청각장애 여부를 선별하는 검사도구이다 (Musiek et al., 2005). GIN의 개발 및 상용화 이후 20 30대 건 청성인(Samelli \& Schochat, 2008; Prem et al., 2012; Choi et al., 2013) 외에도 소아(Shinn et al., 2009), 학령기 아동(Amaral \& Colella-Santos, 2010; Marculino et al., 2011), 건청중년 및 노인군(Park \& Lee, 2015), 건청이명 및 이명난청군(Sanches et al., 2010; Kwon et al., 2015) 등의 다양한 대상군의 결과 가 보고되고 있다. $\mathrm{GIN}$ 검사 시 최소 $35 \mathrm{~dB}$ SL 최대 $50 \mathrm{~dB}$ $\mathrm{SL}$ 의 제시레벨을 사용하라는 과거 선행연구를 통한 권고사항 이 건청청년뿐 아니라 건청노인 혹은 경중도 난청노인군을 대 상으로도 적용이 가능한지 알아보고자 하였다.

먼저, 건청청년의 결과를 살펴보면 본 연구에서 $50 \mathrm{~dB} \mathrm{SL}$ 의 제시레벨에서 측정한 $\mathrm{YNH}$ 군의 GIN 정반응률이 평균 $76.1 \%$ (범위 70 80\%)로 선행연구(Musiek et al., 2005; Choi et al., 2013)에서 제시한 결과 범위와 유사함을 확인하였다. 앞서 설명 하였듯이 GIN의 검사절차에서는 청자의 청력을 기준으로 50 $\mathrm{dB}$ SL에서 자극음을 제시할 것을 권고하며(Musiek et al., 
2005), 특히 건청청년의 경우 자극음 제시레벨이 $35 \mathrm{~dB} \mathrm{SL}$ 이 상만 되면 $50 \mathrm{~dB}$ SL에서 측정한 GIN 결과와 유의한 차이가 없다고 하였다(Weihing et al., 2007). 본 연구 결과에서도 건청 청년, 건청노인, 난청노인 모두 $30 \mathrm{~dB}$ SL 이하의 레벨에서 자극 음을 제시할 경우 GIN 결과가 유의하게 저하되었으므로 Weihing et al.(2007)이 제시한 대로 35 50 dB SL 이내에서 적어도 건청 혹은 고주파수에서만 경중도 난청을 가졌다면 개개인이 편안하면서 충분히 들을 수 있는 제시레벨에서 GIN 검사도구 를 시행하면 좋을 것으로 생각한다.

본 연구에 참여한 건청청년, 건청노인, 난청노인의 GIN 정반 응률과 GIN 추정역치를 비교하였을 때 노화, 난청 모두 gap 탐 지능력에 부정적인 영향을 주어 건청청년보다는 건청노인이, 건청노인보다는 난청노인의 GIN 결과가 유의하게 더 나빴다. 본 연구와 비슷하게 John et al.(2012)은 YNH(n = 50), ENH (n = 28), $\mathrm{EHI}(\mathrm{n}=76)$ 의 세 가지 그룹에게 하나의 제시레벨, $35 \sim 50 \mathrm{~dB}$ SL 중 개인이 편안하면서 크게 잘 들린다고 하는 레 벨에서 GIN 역치를 측정하였다. John et al.(2012)은 하나의 고 정된 제시레벨에서만 GIN을 측정하였으므로 본 연구에서 제 시한 다양한 레벨 중 유사한 결과만을 비교하면 다음과 같다. 본 연구 결과 중 40 50 dB SL에서 측정한 $\mathrm{YNH}$ 군의 평균 $\mathrm{GIN}$ 역치는 4.2 4.8 msec, ENH군의 경우 평균 6.9 7.1 msec이었다 (Figure 3). John et al.(2012)의 분석 결과 양이 간 GIN 결과는 다르지 않았으며, $\mathrm{YNH}$ 의 $\mathrm{GIN}$ 역치는 4.2 5.2 msec(평균: 4.7 $\mathrm{msec}$, 표준 편차: 0.9). $\mathrm{ENH}$ 의 $\mathrm{GIN}$ 역치는 6.1 7.5 msec(평균: $6.6 \mathrm{msec}$, 표준 편차: 1.4)이라 보고하였으므로, 두 연구의 $\mathrm{YNH}, \mathrm{ENH}$ 대상군의 $\mathrm{GIN}$ 역치 범위가 겹침을 확인하였다. 그러나 John et al.(2012)의 연구에 참여한 $\mathrm{EHI}(\mathrm{n}=76)$ 의 평균 GIN 역치는 8.1 9.3 msec(평균: $8.8 \mathrm{msec}$, 표준 편차: 2.5)이었 고 본 연구의 $\mathrm{EHI}$ 군( $\mathrm{n}=12)$ 의 $40 ~ 50 \mathrm{~dB}$ SL에서의 $\mathrm{GIN}$ 역치 는 9.6 10 msec으로 약 0.8 1.2 msec 정도 역치가 더 컸다. John et al.(2012)은 노인그룹 간 그리고 그룹 내 회귀분석을 시 행한 결과, GIN 역치의 개인차는 청력역치로 가장 잘 설명된다 고 보고하였다. John et al.(2012)의 EHI 대상자와 본 연구의 $\mathrm{EHI}$ 대상자의 평균 연령은 약 66세로 동일하나, 본 연구에 참 여한 $\mathrm{EHI}$ 그룹의 주파수별 순음청력역치 중 $8 \mathrm{kHz}$ 를 제외한 $1,2,4 \mathrm{kHz}$ 의 청력역치가 약 5 10 dB 더 컸다. 따라서 본 연구 에 참여한 $\mathrm{EHI}$ 대상자의 청력저하가 $\mathrm{GIN}$ 역치에 영향을 주었 을 가능성을 생각해 볼 수 있다.

난청인이 건청인보다 저하된 gap 탐지능력을 보이는 원인에 대해 Florentine \& Buus(1984), Gelfand et al.(1986), Takahashi \& Bacon(1992), Mazelová et al.(2003), Feng et al.(2010) 등은 고주파수 청력손실 정도와 관련이 있다고 추정하였다. 예 를 들어 Feng et al.(2010)은 신호음의 고주파수 에너지가 청자
의 시간분석력에 영향을 주므로 고주파수에서 청력이 떨어지 는 경사형 난청인이 건청인에 비해 저하된 진폭변조(amplitude modulation)와 GDT를 보였을 것으로 설명하였다. Mazelová et al.(2003), Ok \& Lim(2007) 역시 고주파수에서 난청이 심할 수록 gap 탐지능력이 저하됨을 보고하였다. 이는 본 연구에서 확인한 노인군의 순음청력역치와 GIN 결과 간 상관성과도 일 치한다.

본 연구에서는 자극음제시레벨에 따라 건청성인, 건청노인, 난청노인 그룹 간 GIN 수행력을 비교하였고, 분석 결과 건청성 인이 가장 우수한 GIN 수행력을 난청노인이 가장 저조한 GIN 결과를 보였다. 자극음 제시강도가 증가할수록 GIN 수행력이 향상하는 경향을 보였고, 세 그룹 모두 40 50 dB SL 간 GIN 결과는 유의하게 다르지 않았다. 이러한 결과는 20 30대 건청 성인을 대상으로 한 선행연구 결과를 지지하는 것으로 건청노 인 혹은 경중도 난청노인에게 건청성인과 유사한 $35 \mathrm{~dB} \mathrm{SL}$ 혹 은 $40 \mathrm{~dB} \mathrm{SL}$ 이상의 제시레벨에서 $\mathrm{GIN}$ 검사를 시행하는 것이 가능할 것임을 의미한다. 그러나 본 연구대상자 중 고주파수 청 력손실 정도가 심한 난청노인일수록 저하된 GIN 결과를 보였 으므로, 앞으로 고도 혹은 심도 난청을 가진 난청인 등 다양한 임상그룹을 위한 지속적인 연구가 필요하겠다.

중심 단어 : 자극제시레벨·시간정보처리능력·시간분석력·노인.

\section{REFERENCES}

Amaral, M. I. \& Colella-Santos, M. F. (2010). Temporal resolution: Performance of school-aged children in the GIN - gaps-in-noise test. Brazilian Journal of Otorhinolaryngology, 76(6), 745-752.

Bahng, J. \& Lee, J. (2015). Hearing thresholds for a geriatric population composed of Korean males and females. Journal of Audiology and Otology, 19(2), 91-96.

Bertoli, S., Smurzynski, J., \& Probst, R. (2005). Effects of age, age-related hearing loss, and contralateral cafeteria noise on the discrimination of small frequency changes: Psychoacoustic and electrophysiological measures. Journal of the Association for Research in Otolaryngology, 6(3), 207-222.

Choi, J. H., Kim, Y. K., \& Jang, H. S. (2013). Temporal resolution ability in Korean population by gap-in-noise (GIN). Audiology, 9(2), 148-156.

Feng, Y., Yin, S., Kiefte, M., \& Wang, J. (2010). Temporal resolution in regions of normal hearing and speech perception in noise for adults with sloping high-frequency hearing loss. Ear and Hearing, 31(1), 115125.

Florentine, M. \& Buus, S. (1984). Temporal gap detection in sensorineural and simulated hearing impairments. Journal of Speech and Hearing Research, 27(3), 449-455.

Folstein, M. F., Folstein, S. E., \& McHugh, P. R. (1975). "Mini-mental state”. A practical method for grading the cognitive state of patients for the clinician. Journal of Psychiatric Research, 12(3), 189-198.

Gelfand, S. A., Piper, N., \& Silman, S. (1986). Consonant recognition in quiet and in noise with aging among normal hearing listeners. The Journal of the Acoustical Society of America, 80(6), 1589-1598.

Grose, J. H. \& Hall, J. W. 3rd. (1996). Perceptual organization of sequential stimuli in listeners with cochlear hearing loss. Journal of Speech and Hearing Research, 39(6), 1149-1158. 
Hall, J. W. 3rd., Grose, J. H., Buss, E., \& Hatch, D. R. (1998). Temporal analysis and stimulus fluctuation in listeners with normal and impaired hearing. Journal of Speech, Language, and Hearing Research, 41(2), 340-354.

Harris, K. C., Eckert, M. A., Ahlstrom, J. B., \& Dubno, J. R. (2010). Agerelated differences in gap detection: Effects of task difficulty and cognitive ability. Hearing Research, 264(1-2), 21-29.

Heinrich, A. \& Schneider, B. (2006). Age-related changes in within- and between-channel gap detection using sinusoidal stimuli. The Journal of the Acoustical Society of America, 119(4), 2316-2326.

John, A. B., Hall, J. W. 3rd., \& Kreisman, B. M. (2012). Effects of advancing age and hearing loss on gaps-in-noise test performance. American Journal of Audiology, 21(2), 242-250.

Kwon, H. E, Kim, C. W., \& Lee, J. H. (2015). The effects of tinnitus and hearing loss on results of GIN (gaps-in-noise) and the tinnitus-related subjective handicap. Audiology, 11(2), 108-119.

Kwon, Y. C. \& Park, J. H. (1989). Korean version of Mini-Mental State Examination (MMSE-K): Part I. Development of the test for the elderly. Journal of Korean Neuropsychiatric Association, 28(1), 125-135.

Marculino, C. F., Rabelo, C. M., \& Schochat, E. (2011). Gaps-in-noise test: Gap detection thresholds in 9-year-old normal-hearing children. Jornal da Sociedade Brasileira de Fonoaudiologia, 23(4), 364-367.

Mazelová, J., Popelar, J., \& Syka, J. (2003). Auditory function in presbycusis: Peripheral vs. central changes. Experimental Gerontology, 38(1-2), 87-94.

Moore, B. C., Glasberg, B. R., Donaldson, E., McPherson, T., \& Plack, C. J. (1989). Detection of temporal gaps in sinusoids by normally hearing and hearing-impaired subjects. The Journal of the Acoustical Society of America, 85(3), 1266-1275.

Musiek, F. E., Shinn, J. B., Jirsa, R., Bamiou, D. E., Baran, J. A., \& Zaida, E. (2005). GIN (gaps-in-noise) test performance in subjects with confirmed central auditory nervous system involvement. Ear and Hearing, 26(6), 608-618
Ok, S. J. \& Lim, D. H. (2007). The effects of ipsilateral and contralateral background noises on gap detection thresholds in the elder. Audiolo$g y, 3(1), 36-42$.

Park, J. K. \& Lee, J. H. (2015). A comparison of auditory temporal processing in young, middle-aged, and older adults: Measure of GIN (gapsin-noise) and time-compressed sentence recognition. Audiology, 11(4), 310-319.

Prem, G., Shankar, N. S., \& Girish, N. (2012). Gaps in noise (GIN) testnormative data. American Journal of Medicine, 8(1), 24-27.

Samelli, A. G. \& Schochat, E. (2008). The gaps-in-noise test: Gap detection thresholds in normal-hearing young adults. International Journal of Audiology, 47(5), 238-245.

Sanches, S. G., Samelli, A. G., Nishiyama, A. K., Sanchez, T. G., \& Carvallo, R. M. (2010). GIN test (gaps-in-noise) in normal listeners with and without tinnitus. Pró-fono, 22(3), 257-262.

Schneider, B. A. \& Hamstra, S. J. (1999). Gap detection thresholds as a function of tonal duration for younger and older listeners. The Journal of the Acoustical Society of America, 106(1), 371-380.

Schneider, B. A., Pichora-Fuller, M. K., Kowalchuk, D., \& Lamb, M. (1994). Gap detection and the precedence effect in young and old adults. The Journal of the Acoustical Society of America, 95(2), 980-991.

Shinn, J. B., Chermak, G. D., \& Musiek, F. E. (2009). GIN (gaps-in-noise) performance in the pediatric population. Journal of the American Academy of Audiology, 20(4), 229-238.

Snell, K. B. \& Frisina, D. R. (2000). Relationships among age-related differences in gap detection and word recognition. The Journal of the Acoustical Society of America, 107(3), 1615-1626.

Takahashi, G. A. \& Bacon, S. P. (1992). Modulation detection, modulation masking, and speech understanding in noise in the elderly. Journal of Speech and Hearing Research, 35(6), 1410-1421.

Weihing, J. A., Musiek, F. E., \& Shinn, J. B. (2007). The effect of presentation level on the gaps-in-noise (GIN) test. Journal of the American Academy of Audiology, 18(2), 141-150. 